\section{REVIEW OF MARY MIDGLEY'S ANIMALS AND WHY THEY MATTER}

\author{
DONALD VANDEVEER \\ North Carolina State University
}

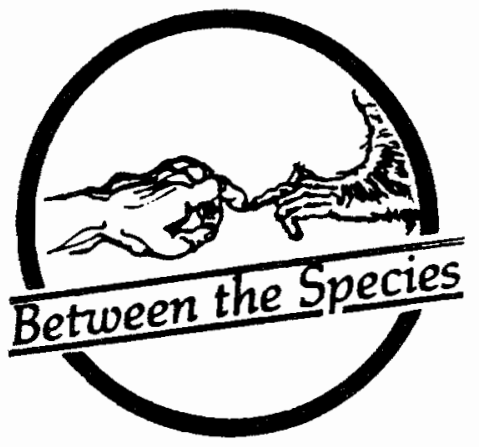

tion of the book's focus is in order. Much of the book is devoted to identifying those doctrines, quasi-articulated reasons, attitudes, and psychological shards which tend to block us from thinking clearly about (nonhuman) animals and about our moral relationship with them. That these obstacles are very great is born out by the enormous neglect of such matters by most of the thinkers that we label "the greats." It is also born out by name-calling, disdain, and cheap shots that emanate from people who, on certain topics, are among the best and brightest-from ordinary people down to scientists and philosophers. Although a good deal of work has occurred--analyzing the arguments concerning duties toward, or rights of, animals --in the last decade or so, we still hear the same shoddy claims or arguments fron those who do not question the status quo, e.g., we lack contractual relations with animals, they don't talk (as we do), they are not moral agents, not experimenting on them would impede science, maybe they lack feelings, after all they're not human, and so on. As if such considerations are all true, or if true, as if they clearly settled the disputes. Midgley, with understanding, fairness, and care dismantles a good number of these views, in particular those which appeal to natural competition, to the claim that those who believe in duties to animals are too emotional, to rationalist considerations (which tend to deny that justice is owed to the nonrational or those not self-conscious, e.g.. Hume, Kant, and Rawls). In a later chapter (7), Midgley tellingly illustrates how some of "the greats" (e.g.. Hume, Kant, and Rousseau) tend to lose, or not employ, their
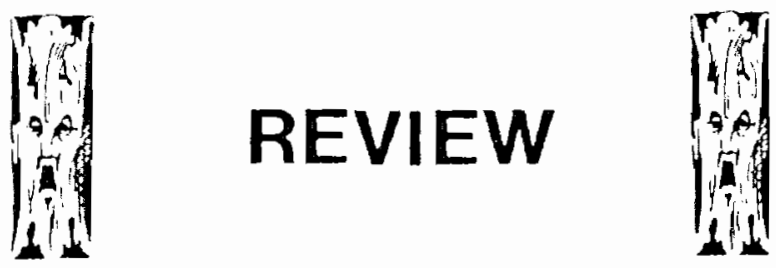
rational capacities on certain topics, e.g., the treatment of women. Thus, Rousseau claims that "woman is specially made for man's delight." The point of this attention to consideration of historical attitudes toward women, slaves, or the "Indians" in America is, of course, to illustrate our most imperfect rationality, i.e., our capacity to both think clearly on some topics and have a kind of intellectual melt-down on certain issues. Thus, our myopia (to switch metaphors) about animals is not unusual. There has been a problem about getting people to think more clearly by teaching them some logic. I still believe the practice useful, but as the cases mentioned suggest, people still just do not think at all when it comes to certain issues, or else their reasoning capacities seem to be on vacation. Midgley is sensitive to this and illustrates well how our prejudices and ambivalences cloud our thinking about animals.

The book functions to enlighten as the Germans would have it, an Aufklarung, a clearing up; it helps sweep away much of the historical intellectual trash which prevents us from taking animals seriously. Why should we do so? Midgley.'s answer, in brief, is that we should in many cases for reasons quite similar to the reasons we take people seriously, i.e., why they matter.

What follows with respect to how we should treat thern? on this crucial point we hear little in this volume. Midgley speaks judiciously and cautiously. She is not obviously an all-out utilitarian, and she gives no evidence here of believing that animals have rights (in some sense beyond merely being objects of duties). Unlike the positions of Peter Singer and Tom Regan, she does not beat the drum for an abolition of factory-farming, most or all experimentation on animals, or most or all hunting. Does she believe animals (or some) have "equal inherent value" (as do, let us assume, normal people) or that equal interests (animal or human) should be given equal moral weight? If I read her correctly, the answer is negative, or perhaps, that we do not know. She does suggest that there are serious problems about

the exchange-rate at the speciesbarrier. - this rate can indeed not be set, quite at par--that "speciesism" is not just an irrational prejudice. (p. 26)

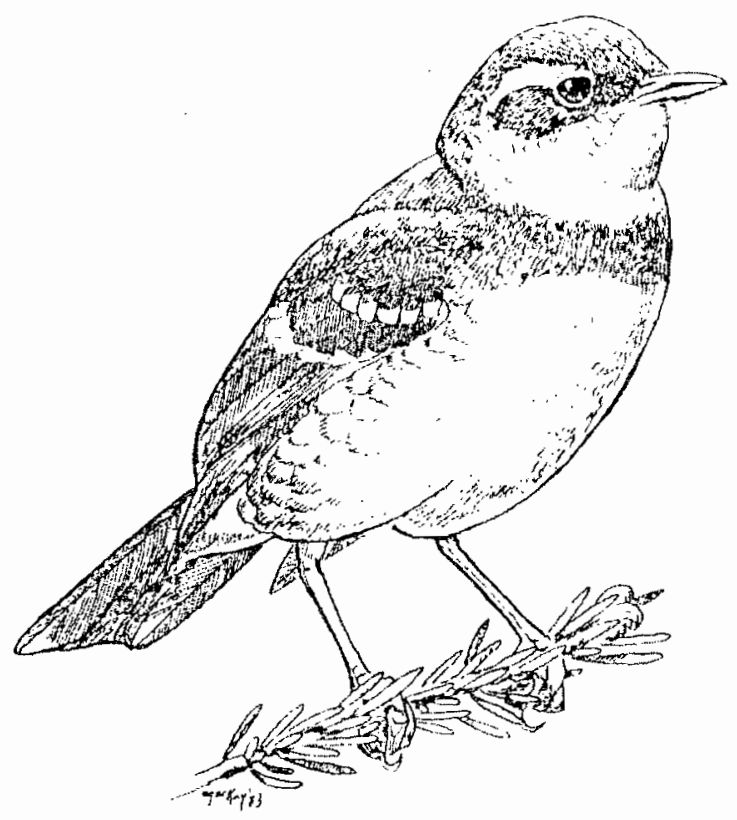

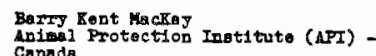

Thus, Midgley is unwilling to accept certain radically egalitarian (across species) views as well as the traditional "absolute dismis" sal" of the view that animals matter. This quasi-moderate position is, I believe, the right one (as I have argued elsewhere).[1] However, the implications of this outlook need to be developed and articulated further.

So, much is left undone in this volume, but it is a wise little book. Too many discussions fixate only on whether animals matter and why. Midgley tries to settle these matters. Next, we need to focus on how much they matter and what follows vis-a-vis our dealings with thern. Midgley does not in this volume try to settle these ratters. [2] Concerning them, we need careful argument for here perplexities and emotions run deep. on this point, I believe Midgley would agree.

Notes

1. See "Interspecific Justice," in Peoople, Penguins, and Plastic Trees, edited by myself and Christine Pierce (Wadsworth, 1986).

2. This reviewer has not, however, read Midgley's volume, Beast and Man. 


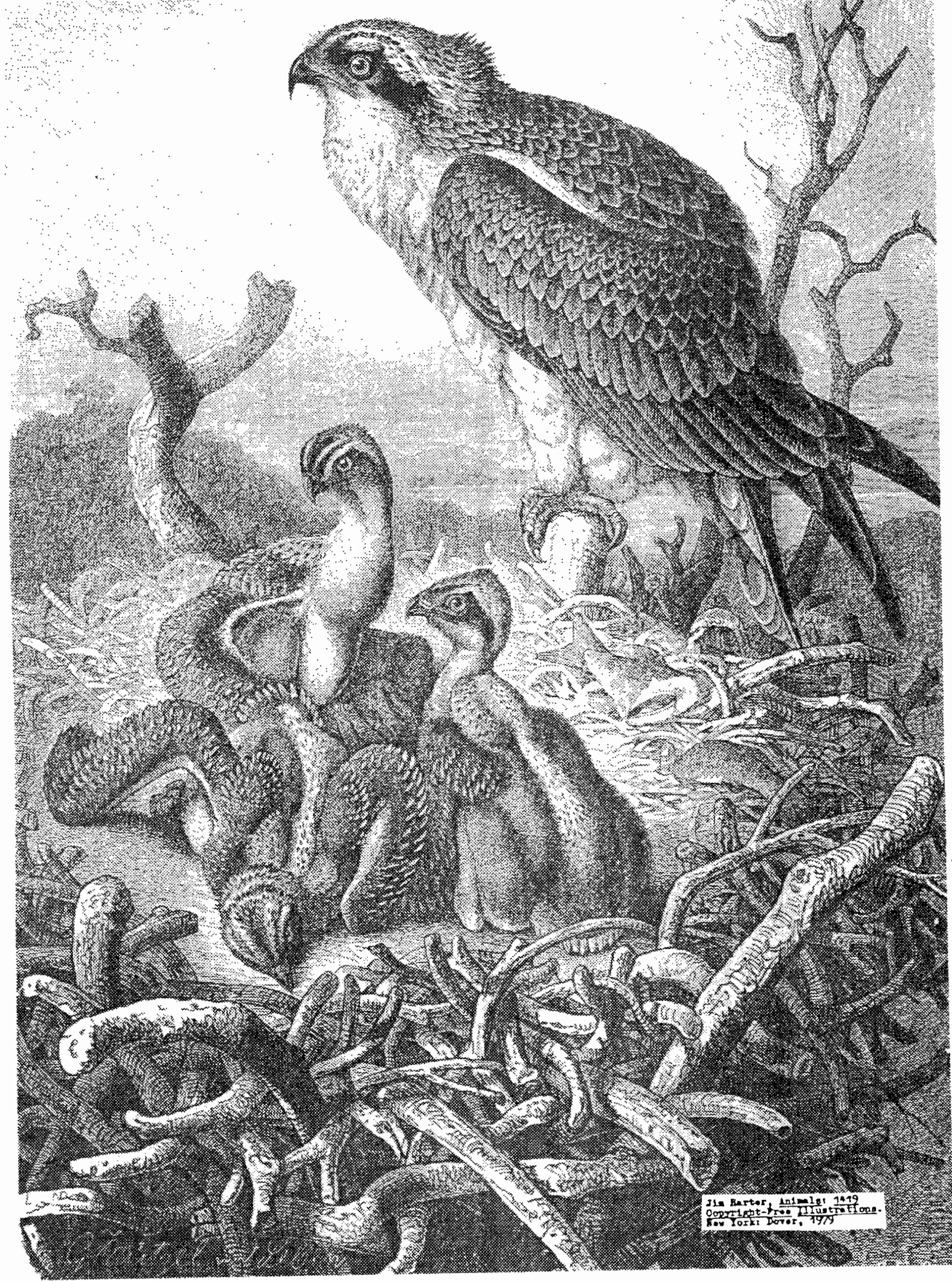

